\title{
The Current Situation and Development Trend of Dance Teaching in Colleges and Universities
}

\author{
Li Qian \\ Dance Institute, Yunnan Arts University, Kunming 650000, China \\ liqianyn@126.com
}

Keywords: colleges and universities, dance teaching, current situation, development trend

\begin{abstract}
With the continuous development of education, college dance teaching has also been highly valued. Dancing is also one of the art teaching processes in colleges and universities, and it also provides appropriate directions for the future development of students. This paper will focus on the status quo of college students' dance teaching, put forward the development trend of dance teaching in colleges and universities, hoping to improve the leadership and teachers' attention to to dance teaching.

College dance is a new development trend of education development, focusing on improving students 'dance ability and their dance qualities, promoting the all-round development of students, expanding the students' future employment and increasing the employment rate of students. Students in the dance at the same time also improve their own physical fitness, cultivate their own sentiments, contribute to the overall quality of physical and mental development of students. However, there are various problems in the dance teaching in colleges and universities at present in China. This paper studies the current situation and development trend of the dance teaching in colleges and universities. The report is as follows.
\end{abstract}

\section{The status of college dance teaching}

\subsection{Complicated teaching content}

College dance teaching can relieve the fatigue of students, make students feel happy and reduce the pressure of students' learning. They can also invest more into learning after the dance training to improve the learning efficiency. It can be seen that the dance teaching in colleges and universities is of practical significance to college students. However, there are some problems in the dance teaching in colleges and universities in our country, which have some obstacles to the students' dance training. At present, the content of dance teaching in colleges and universities in our country is rather complicated. The overall design of dance is lack of rationality. The content of dance teaching includes Latin dance, hip-hop dance and ballroom dance. However, due to the limited time of students, teachers 'teaching ability and students' ability to receive dance training. And other factors lead to some contradictions between students and dance teaching, is not conducive to student dance training.

\subsection{Lack of teaching resources}

At present, the dance teachers in colleges and universities have limited teaching ability and do not fully understand the development history, evolution history, the standardization of dance decomposition movements and the deep expression of the dance movements, etc., and can not give the students a careful explanation so that the dance class of the teaching content is more monotonous, can not improve students' interest in learning dance; college dance equipment provided to students is the projector, without the dance of correction equipment and sports equipment, etc., on the dance training students did not play a positive role in promoting and supporting role ; Most universities do not set up a special dance classroom, but in the gymnasium and other places for practice, poor teaching environment; dance props and clothing preparation is 
very small, restricting the students' dance training [1].

\subsection{A single teaching method}

College dance teachers dance teaching methods for students is more monotonous, teaching is a unified fixed mode, can not fully mobilize the students interest in learning. Dance teachers in the teaching process emphasizes the normative and coherent dance moves, so teaching will give students a full set of dance presentation, but students have different dance based on the teacher's dance shows only exist in the foundation Of the action, and the memory is more ambiguous, confusing memory before and after the action, coupled with the students' limited learning time, the lack of teacher resources makes the guidance of students almost no time, students in the process of learning dance gradually accumulated problems, making students Dance learning is a failure, loss of interest in learning, teachers' interest in teaching also gradually declined, leading to the gradual decline of the quality of dance teaching in colleges and universities, restricting the development of dance teaching in colleges and universities.

\subsection{Other aspects}

At present, most of the personnel trained by ordinary universities focus on the ability of scientific thinking, and the image of artistic thinking can improve and influence and promote the logical thinking of science. Although scientific thinking is rigorous, abstract, and artistic thinking of the sensual, visualization are essentially different, but in fact, people's thinking is complex, non-linear, with complex features. Artistic thinking has the characteristics of perceptual image. When it is combined with scientific thinking, the organic combination and interaction of the two can broaden people's thinking space, inspire and make up logical thinking, and help scientific thinking succeed. Therefore, art education in institutions of higher learning, especially those in the mainstream of agricultural science, if neglected in combination with scientific and technological research activities, will be out of step with the true quality-oriented education.

On the basis of cultivating college students 'artistic skills, dance education should pay more attention to cultivating students' artistic appreciation ability, artistic evaluation ability and unique artistic insight on things, and should also transform dance and other humanities and social subjects into comprehensive sensibility, that is, The emphasis of dance education should shift from the ontology of dance to the combination with other disciplines, such as aesthetics, philosophy, psychology, sociology and architecture. For example, practice lessons should emphasize the popularization of dance knowledge. When we enjoy class, when we finish the author, creative motivation, performance content, structure appreciation, the content of the class should be further extended to inspire students to change their feelings from art, art sociology, art psychology, art philosophy Angle expounded, thereby enriching and improving the quality of art education.

At present, most of the art courses offered in institutions of higher learning in our country are mainly elective courses. The courses offered can be divided into three categories: one is skill-based courses such as singing skills, various instrument learning and dancing The selection of works, the number of elective courses such as the number of doors, due to the various colleges and universities have the venue, funding, teacher resources and restrictions vary; the other is to solve the students must choose to art course Such as basic music theory and dance motif, such elective courses generally have colleges and universities; the third category is to enjoy classes, different schools to open such elective courses vary, there are Classical music appreciation, there are national music appreciation, Western music appreciation, music through the music appreciation, there opera opera or repertoire appreciation, as well as simple thematic music appreciation and dance works to enjoy (some colleges and universities, etc. The proportion of the above three types of courses in art elective courses varies from university to university and does not have a unified and complete syllabus and assessment standard. 


\section{Development Strategy of Dancing Teaching in Colleges and Universities}

\subsection{Rational design of teaching content}

College dance teaching is an indispensable part of college teaching, which contributes to the cultivation of students' emotion, the enrichment of life content and the expansion of future employment. Therefore, the existing problems in the design of college dance teaching content are solved, and the corresponding solutions. Firstly, the content of college dance teaching is analyzed according to the situation of the school itself, and its arrangement is improved and reasonable arrangements are made to understand the students 'interest in learning the dance type and the teachers' own abilities. Then, the practical application of various kinds of dance in social life The situation of investigation and statistics, make a comprehensive evaluation, and finally combine all aspects of the request to make a scientific and reasonable program of dance teaching, teachers and students to facilitate the common progress of dance ability and dance teaching in colleges and universities further development.

\subsection{Actively improve teaching resources}

In addition to the reasonable design of college dance teaching content, but also need to pay attention to the college dance teaching teachers strength and teaching environment, equipment and other issues. Therefore, it is necessary to conduct an investigation on the teachers' ability in college dance teaching to understand and reasonably arrange the resources of teachers; to set up special dance classrooms, to install glass on four walls of the classroom, to equip suitable dance equipment, to improve classroom floors, and to maximize the size of dance classrooms Expand, develop dance clothing for students, provide students with a unified dance counseling and encourage students to train themselves, understand the students 'existing dance problems, and provide solutions to these problems so as to enhance students' enthusiasm for learning about dance. In addition, we must also regularly carry out professional training for dance teachers to improve teachers' dance qualities and continuously improve the quality of dance teaching.

\subsection{Optimize innovative teaching methods}

The change of teaching methods plays an important role in the process of dance teaching in colleges and universities. With students as the main body, the teachers give the students a video playing standard dance movements and encourage students to imitate the training. The teachers give the correct instruction according to the students' learning situation. Competition can be used to promote students to practice the prescribed dance moves within a certain period of time, and then compete to reward outstanding students and make them perform to students to arouse the enthusiasm of students to learn and promote students' ability to dance, and then improve the overall level of school dance teaching. Conclusion Dance teaching in colleges and universities occupies an important position in the process of teaching in colleges and universities, adjusting students 'intense learning atmosphere, enriching students' own emotions and providing students with more choices in future employment. In this paper, the status quo of college dance teaching is introduced, including the complicated teaching content, the lack of teaching resources and the single teaching method. Based on the analysis of these problems, the author puts forward the countermeasures for the development of dance teaching in colleges and universities: rationally designing teaching contents, improving teaching resources, optimize innovative teaching methods, improve students' ability to dance, and promote the improvement and development of school dance teaching quality.

\subsection{Other aspects}

At the same time of guiding college students to enter the art hall, ordinary college art education should pay more attention to the cultivation of college students' abilities. Only by cultivating students' imagination, creativity and artistic thinking ability can we develop scientific wisdom in the process of quality education to serve science education. In view of the current situation of art education in ordinary colleges and universities in our country, I think that dance education should 
be carried out in the following aspects.

The implementation of the "one master, multiple assistant" curriculum system obviously does not give the idea of a dance art course as the main course in colleges and universities. In fact, the more types of dance art classes are offered, the more subdivisions are, the more students have no choice. Therefore, a large number of dance electives should be systematized and scientifically lengthened to reduce the number of classes. Regardless of the type of subjects offered, starting with quality education, the most important thing is to set up an asymptotic and complex course in the content system, that is, according to the students' physical condition and learning ability, On the basis of explaining the basic theory of dance art, through appreciation of art works, analysis and appreciation of art works from the perspective of other arts and social sciences. Dance art course should be based on this course, supplemented by other courses. At the same time, it is necessary to carry out the purpose of art quality education. In the setting of auxiliary dance art courses, some elective courses of interdisciplinary courses such as dance aesthetics, dance psychology, dance sociology, and philosophy of art should be set up to meet the different needs of students. The company is located in:

Pay attention to the form of practical education, in the process of quality education in dance arts, in addition to the form of classroom teaching, but also carry out some campus cultural activities. For example, dance exchange associations, salons, workshops and the like. In carrying out such activities, apart from having a certain breadth and depth, activities should be organized for students of different artistic levels. Art key elements can be used as a "point" to drive ordinary students, stimulate college students' interest in and interest in dance art, and set up dance groups and art studios spontaneously. Expand exchanges and cooperation among students, apply their ideas in the process of creation and practice, and deepen the theory in practice so as to achieve the goal of training qualified personnel through art education.

In short, at present, the dance education in ordinary colleges and universities needs to re-establish the training objectives, that is, to shift the focus of technical education to the comprehensive development of art quality and scientific quality education. The comprehensive development of art quality also requires that the dance art education and science education be organically integrated to achieve mutual promotion and positive interaction between the two and thus play a cross-complementing role in cultivating high-quality talents of a complex type. Training objectives is the direction and standards for the growth of qualified personnel, is the premise and guidance of all teaching activities. The turning point of college dance education in training objectives will affect the practice of dance teaching such as course design, instructional design and activity organization. It will put forward more requirements for teachers of dance arts education and will push forward the artistic quality of ordinary university students. To a higher level, and ultimately comprehensively enhance the overall quality of college students.

\section{References}

[1] Li Lei. On the existing problems and current situation of dance teaching in colleges [J]. CAI ZHI, 2014, (3).

[2] Shen Yi. Current Situation and Development Strategies of College Dance Teaching [J]. The Voice of the Yellow River, 2015, (22).

[3] Pingxin dance education: an important quality education [J], Beijing Dance Academy Journal, 1999.

[4] Pingxin dance aesthetic education and quality education [J], Beijing Dance Academy Journal, 1999.

[5] Liu Qingyi. Correspond to the new century. Beijing Dance Academy "Dance" discipline positioning and construction [J], Beijing Dance Academy, 2002.

[6] Liu Qing Yi. Reflect: the basis of the study of dance culture [J], Beijing Dance Academy Journal, 2002. 